\title{
Impacto da Implantação do Custo do Pedágio na BR-163 em Relação ao Transporte de Soja do Estado de Mato Grosso ${ }^{1}$
}

\author{
Osmar Torres², Mayra Batista Bitencourt Fagundes ${ }^{3}$, \\ Adriano Marcos Rodrigues Figueiredo ${ }^{4} \mathrm{e}$ \\ Cicero Antonio de Oliveira Tredezini ${ }^{5}$
}

Resumo: Este artigo tem por objetivo a análise da concessão da rodovia BR-163, considerando as possíveis implicações sobre a competitividade no transporte da soja do estado de Mato Grosso. Esta proposição se justifica, sobretudo, porque o pedágio, a priori, representa custo ao transporte rodoviário, qualquer gasto acrescido a ela poderá comprometer a margem de lucro. Esta pesquisa foi subsidiada por revisão bibliográfica e documental, utilizando de pesquisa do tipo descritiva. Buscou-se identificar os principais componentes do custo do transporte rodoviário e o impacto da rodovia concedida na competitividade do setor. Assim, foi feita uma análise comparativa do custo do transporte de soja em rodovias pagas (concedidas) e as economias com custos que são inerentes a esta modalidade de transporte, decorrente da ótima condição da pavimentação asfáltica. Para perpetrar essa verificação e contrapor os custos com pedágio, foram elencadas três variáveis, são elas: (i) a economia com o combustível, (ii) a economia com o custo operacional dos caminhões e (iii) a economia que se faz em menor perdas de grãos de soja. O resultado encontrado após a quantificação das variáveis econômicas apontou impacto positivo, com benefícios econômicos para o estado de Mato Grosso.

Palavras-chaves: Agronegócio, competitividade, política pública, concessão de rodovia.

Abstract: The purpose of this article is to analyze the lease of the BR-163 highway, considering the possible implications on the competitiveness of soybean transport in the state of Mato Grosso. This proposition is justified especially because the toll, a priori, represents cost to the road transport and

1. Data de submissão: 4 de abril de 2016. Data de aceite: 11 de junho de 2017.

2. Universidade Federal de Mato Grosso do Sul, Campo Grande/Mato Grosso do Sul. Brasil. E-mail: osmartor@gmail.com

3. Universidade Federal de Mato Grosso do Sul, Campo Grande/Mato Grosso do Sul. Brasil. E-mail: bitencourtmayra@gmail.com

4. Universidade Federal de Mato Grosso do Sul, Campo Grande/Mato Grosso do Sul. Brasil. E-mail: amrofi@gmail.com

5. Universidade Federal de Mato Grosso do Sul, Campo Grande/Mato Grosso do Sul. Brasil. E-mail: cicero.tredezini@gmail.com 
any additional expense to it may compromise the profit margin. This research was subsidized by bibliographical and documentary revision, using the descriptive research method. The main components of the cost of road transport and the impact of the highway leased on the competitiveness of the sector were identified. Thus, a comparative analysis of the cost of soybean transportation in paid highways (leased) and the cost savings that are inherent to this modality of transportation, due to the excellent condition of asphaltic paving, was performed. To carry out this verification, and to counter toll costs, three variables were listed: (i) the economy with fuel, (ii) the economy with the operating cost of trucks and (iii) the economy that is made in smaller losses of soybean grains. The results found after the quantification of economic variables showed positive impact, with economic benefits for the state of Mato Grosso.

Key-words: Agribusiness, competitiveness, public policy, highway lease.

Classificação JEL: R420.

DOI: http://dx.doi.org/10.1590/1234-56781806-94790550307

\section{Introdução}

A logística de cargas, conjuntamente ao modal rodoviário, tem primordial importância para o escoamento dos produtos primários no País. Porém, atenta-se para o fato de que a soja brasileira, e especialmente a do estado de Mato Grosso, tem perdido competitividade no mercado externo devido a gargalos da logística, como à precariedade das rodovias que resulta, principalmente, em alto custo no escoamento da produção, acrescendo o custo final da mercadoria em até $25 \%$, com variações vinculadas à distância (CORREA e RAMOS, 2010; IMEA, 2015).

Com a finalidade de melhorar a trafegabilidade de veículos e especialmente promover maior competitividade aos setores econômicos no escoamento da produção e, assim, superar o gargalo logístico, o governo federal transferiu para a iniciativa privada, por meio de concessão pública, a operação, recuperação, manutenção, ampliação e a duplicação de trechos da BR-163 localizado no estado de Mato Grosso.

No entanto, devido às especificidades da economia do estado, essencialmente baseada na agropecuária, como soja, milho, carne bovina, algodão, cana-de-açúcar, dentre outros (CONAB, 2015), cabe à indagação: é possível ganhar competitividade em rodovia pedagiada?
Este artigo tem por objetivo a análise da concessão da rodovia BR-163, considerando as possíveis implicações para ampliar a competitividade no transporte da soja do estado de Mato Grosso. Esta proposição se justifica, sobretudo porque o pedágio, a priori, representa custo ao transporte rodoviário. E ao se tratar de mercadorias primárias, de baixo valor agregado, isto é, produtos com negócios relacionados à escala de produção, em que a atuação se dá especialmente na minoração dos custos finais, qualquer gasto acrescido poderá comprometer a margem de lucro de seus produtores (PORTER, 1989; FLEURY, 2005).

Dentre os grãos produzidos nestes estados, elegeu-se especificamente a soja para realizar este estudo, pela sua extrema importância na economia brasileira e por tratar-se de produto de exportação. A ênfase deste estudo aplica-se ao estado de Mato Grosso, sobretudo por se destacar como polo produtor de soja, e utilizar o modal rodoviário como o principal meio de transporte e escoamento da produção dos grãos até aos portos (CORREA e RAMOS 2010; IMEA, 2015).

Para tanto, utilizou-se de uma análise qualitativa. Segundo Richardson et al. (1999), a escolha da abordagem, seja qualitativa ou quantitativa, se dará pela natureza do problema e pelo nível de aprofundamento. Ademais, são diferenciadas entre si, além da forma do problema, também pela sistemática pertinente a cada um deles. 


\section{Revisão da literatura}

\subsection{O transporte de carga brasileiro}

Nos últimos anos, principalmente com a abertura de novas áreas sobre a vegetação de Cerrado, o Brasil passou a ser produtor de soja de grande destaque, tendo apresentado na safra 2013/2014 a produção total de 87,5 milhões de toneladas de grãos, em área plantada de 24,2 milhões de hectares, com produtividade média de 3.106 kg ha-1 (CONAB, 2013).

Nesse contexto caracterizado, sendo o País grande produtor e exportador não só de soja, mas como de outras commodities de grande destaque no mundo globalizado, existe a necessidade de uma logística adequada e eficiente para o escoamento devido de toda essa produção. Entretanto, o País falha ao planejar, implementar e controlar o fluxo e a armazenagem desses produtos, bem como a cadeia envolvida nesse processo que visa a atender aos objetivos dos consumidores e ser líder no setor (FLEURY, 2006).

A Confederação Nacional de Transporte (CNT) divulgou o boletim estatístico em 2015, a matriz do transporte de cargas do Brasil, que afirma que, em 2014, a distribuição de modais se manteve focada no transporte rodoviário que representou $61,1 \%$ da matriz de transporte nacional, movimentando 485 milhões de toneladas por quilômetro útil - TKU6; o ferroviário apresentou participação de 20,7\%, com 164.809 milhões de TKU e o hidroviário foi de 13,6\% com 108.000 milhões de TKU. As rodovias permanecem sendo os principais responsáveis pela maior parte do transporte de carga do País (CNT, 2015).

A dependência excessiva do transporte de carga na modalidade rodoviária é evidenciada ao compará-la a outros países, especialmente aqueles países com dimensões territoriais semelhantes ao Brasil, a exemplo, do caso dos Estados Unidos, que também é o principal concorrente no setor da soja, no mercado internacional. A participação dos EUA no módulo modal rodoviário em transporte de cargas é de $26 \%$, na Austrália, $24 \%$, e na China, apenas $8 \%$ do total, sendo que para

6. Tonelada Útil (TU) - Total de carga movimentada no transporte remunerado, sendo TKU - Unidade de medida equivalente ao transporte de uma tonelada útil à distância de um quilômetro, conforme terminologia básica da ANTT. transporte de longa distância utilizam os modais hidroviário e ferroviário (BARTHOLOMEU, 2006).

Quanto à Argentina, apesar de o transporte de soja ser altamente concentrado no setor rodoviário, num percentual que permeia os $82 \%$, o setor produtivo de soja se mantém a uma distância média de 250 a 300 $\mathrm{km}$ dos seus principais portos, como de Rosário e de Santa Fé, o que lhe dá vantagem ao escoar a soja já que diminui o custo de transporte (SILVA FILHO e LIRIO, 2004). Tais distâncias são relativamente pequenas, se comparadas às do Brasil, que tem uma vasta amplitude: varia desde $200 \mathrm{~km}$, como é o caso da cidade de Ponta Grossa, no Paraná, até 2.270 km, que é a distância de Sapezal (MT) ao porto de Paranaguá (PR).

Em um país no qual o modal rodoviário é o principal meio utilizado para o transporte, é esperado que suas estradas estivessem em boas condições para que lhe gerassem mais competitividade ao escoar seus produtos. O Brasil tem $1.720 .607 \mathrm{~km}$ de estradas, sendo apenas $213.229 \mathrm{~km}$ das estradas pavimentadas, cerca de $12,4 \%$, segundo pesquisa da CNT que faz um levantamento das condições das estradas brasileiras desde 1995 (CNT, 2015).

Quando estratificado por estados, São Paulo apresentou o melhor resultado, tendo avaliação de ótima e boa de $83,5 \%$, sendo, também, o estado que tem o maior número de rodovias sob a administração da iniciativa privada, já o estado de Mato Grosso tem $40 \%$ e Mato Grosso do Sul, 44\% de suas rodovias em condições ótimas e boas (CNT, 2015).

A Figura 1 demonstra as condições das rodovias brasileiras nos últimos 11 anos e como a sua qualidade tem oscilado durante esse período. Atualmente, o levantamento realizado pela Confederação Nacional do Transporte abrange toda a extensão pavimentada das rodovias federais.

Em 2005, a CNT analisou $81.944 \mathrm{~km}$ de estradas e somente $28 \%$ dessas estavam em condições consideradas boas ou ótimas. Pelo gráfico observa-se que houve melhora desse percentual até 2011, quando chegou a $42,6 \%$ dos $92.747 \mathrm{~km}$ pesquisados. Porém, a CNT ampliou a sua população amostral em 2015, chegando a ultrapassar $100.000 \mathrm{~km}$ de estradas. Nota-se que o percentual de estradas boas se manteve na pesquisa, sendo $42,7 \%$ em boas ou ótimas condições, mas ainda $57,3 \%$ estão em condições regulares, ruins ou péssimas. 
Figura 1. Qualidade das rodovias brasileiras de 2005 a 2015

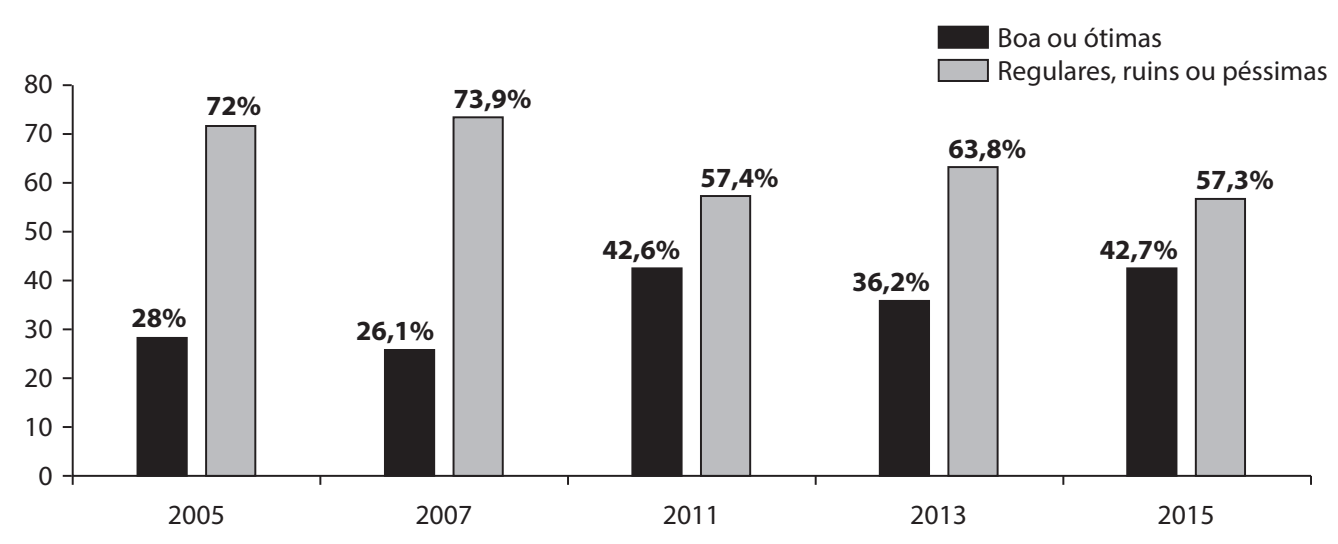

Fonte: Pesquisa CNT de rodovias (2014). Elaborado pelo autor.

\subsection{Componentes do custo no transporte rodoviário de soja}

Berger (1975), que buscou conhecer estes determinantes do frete rodoviário com a finalidade de minimizar o custo de transporte para madeira, chegou à conclusão de que a distância é o fator mais importante no custo do transporte, mas também destaca outras características que podem alterar os custos, tais como: qualidade das estradas, intensidade do trânsito, densidade da produção e produto transportado.

Mais tarde, Correia Junior (2001) procurou, através de uma análise econométrica, explicitar a influência de diversos fatores para a determinação dos valores de frete praticados no transporte da soja a granel, durante três anos desde 1998 até 2000 no transporte da safra dos estados do Paraná, Goiás e Mato Grosso. Assim como Berger, para Correia Junior a distância percorrida ainda foi o principal fator encontrado. Além da distância os resultados mostraram que os valores dos fretes praticados naquele período foram influenciados também por outros fatores como: a existência de praça de pedágio, a sazonalidade da demanda do transporte e as condições das vias utilizadas. Na mesma direção, Gameiro (2003) acrescenta como variável importante às regiões de origem e destino, além da época de embarque.

A composição do preço do transporte rodoviário, para Caixeta Filho e Martins (2011), é feita por arranjos que incorporam os custos da atividade como também fatores locais e conjunturais, que listam uma série de variáveis que influenciam no estabelecimento do preço do frete, a saber: distância percorrida; especificidade da carga transportada e do veículo utilizado; prazo de entrega da carga; custos operacionais; sazonalidade da demanda; perdas e avarias; características e aspectos geográficos das vias utilizadas; pedágios e a possibilidade da carga de retorno para as zonas de origem.

Bartholomeu (2006), em sua tese de doutorado, mensurou os impactos econômicos e ambientais consequentes do estado de conservação das rodovias brasileiras. E apontou que, no caso específico do estado de Mato Grosso, as condições da via parecem ser um destaque devido à má conservação.

Tornou-se consenso entre os pesquisadores que as características das vias exercem impacto direto nos custos do transporte da soja (CORREA Jr, 2001; CORREA Jr. e CAIXETA FILHO, 2003; GAMEIRO, 2003; NTC, 2015). Dos parâmetros acima relacionados, focaremos somente naqueles em que a concessão da BR-163 exerce impacto direto. Entendendo que a concessão representa primeiramente as melhorias, sendo na pavimentação, sinalização e geometria das estradas, em segundo lugar a contraprestação aos concessionários se dará mediante cobrança de pedágios do usuário do serviço público.

\subsubsection{Impacto econômico da rodovia no transporte rodoviário de soja}

Nesta pesquisa assume-se que as condições das vias interferem diretamente em três variáveis: no consumo combustível e no custo operacional dos caminhões ao transportar a soja (BARTHOLOMEU, 2006; REIS, 2006; CAIXETA FILHO, 2008; NTC, 2015); e ainda 
têm ligação direta também com as perdas de grãos de soja pelo caminho (CONAB, 2004; ORNAGHI, 2015).

Neste estudo buscou-se mensurar os ganhos econômicos advindos de rodovias concedidas através da análise das seguintes variáveis:

a) A perda de grãos de soja;

b) Consumo de combustível;

c) Custo operacional;

d) Valor do pedágio.

\section{a) Economia com a não perda da soja}

A quantificação da perda de soja durante o trajeto do transporte pela BR-163 será efetuada conforme o modelo utilizado no item 3.1. Entendendo que em rodovias em que a pavimentação se encontra em ótimo estado as perdas de soja pela estrada assemelha-se a $0,00 \%$. Sendo assim, espera-se que, nos trechos concedidos, a rodovia passe à condição ótima. Logo, há de se minimizar as perdas em $0,15 \%$ em estradas boas, $0,30 \%$ em regulares, 0,45\% em condições ruins e de 0,6\% naquelas que se encontram em péssimas condições de pavimentação.

Considera-se que nos trechos que perpassam pela BR-163/MT os prejuízos com perdas de grãos assumem o índice de $0,3 \%$ a cada $1.000 \mathrm{~km}$, devido à pesquisa CNT (2014) ter classificado sua pavimentação como regular. Da mesma maneira trechos que perpassam pela BR-163/MS, em que a pavimentação da rodovia estava em condições boas antes da concessão, calcula-se que, com a melhora da via para uma condição ótima, haverá de se economizar 0,15\% em perdas.

Esses percentuais serão adequados conforme a distância percorrida em ambos os trechos dos estados de Mato Grosso e Mato Grosso do Sul. Podendo considerar que, em estradas de condições regulares, a cada $1.000 \mathrm{~km}$, a perda será de $0,3 \%$, que corresponde a $0,0003 \%$ a cada $1 \mathrm{~km}$, podendo este percentual ser multiplicado pela distância percorrida.

A intenção é computar em valor monetário o quanto se perde pelo caminho no transporte de soja e o quanto o prejuízo poderá compensar no custo do pedágio em rodovia concedida.

Além disso, tais informações servirão de argumento para combater as perdas e, assim, auferir condições melhores de competitividade, provendo melhores retornos sobre a atividade da soja.

\section{b) Economia com o consumo de combustível}

Entende-se que o consumo de combustível está relacionado à conservação da pavimentação da rodovia. Lima (2006) estimou os custos logísticos com combustível. O autor registra que, em 1996, o diesel representava $16,8 \%$ do custo total de uma carreta, aumentando a sua participação para 31,8\% em 2004. Ainda segundo o autor, o gasto com combustível de um caminhão percorrendo rodovias em condições ótimas de conservação será diferente se o mesmo caminhão trafegar em trechos condições péssimas, ruins, regulares ou mesmo boas.

Segundo a pesquisa da CNT sobre rodovias (2014, p. 342), "a autonomia de um veículo que transita em uma rodovia em condições adequadas de pavimentação em relação a uma não adequada é, em média, $5,0 \%$ superior". O que confirma o que antes fora apresentado pela Escola Superior de Agricultura Luiz de Queiroz (ESALQ/USP) de que as condições de pavimentação exercem influência direta no desempenho energético do transporte rodoviário de cargas (CNT, 2014).

Bartholomeu e Caixeta Filho (2008) pesquisaram a economia de combustível em rotas em condições de conservação distintas. Concluem que o desempenho verificado pelos veículos apresentou diferença quando é percorrida rodovia melhor conservada: a rota Campo Grande ao porto de Santos foi a mais eficiente, resultando em consumo médio de $0,5485 \mathrm{l} / \mathrm{km}$, enquanto a rota entre Rondonópolis e Campo Grande obteve $0,5913 \mathrm{l} / \mathrm{km}$, o que representa economia de $7,8 \%$ no consumo de combustível.

Esse resultado foi utilizado para mensurar a economia com combustível em distâncias específicas pela BR-163, fazendo o cálculo por quilômetro rodado. Para isso, buscou-se o preço médio do diesel em Mato Grosso e Mato Grosso do Sul em fevereiro de 2016, sendo de $\mathrm{R} \$ 3,30$. E ainda considerou-se o rendimento médio do caminhão Volvo FH 540, que é 1,9 km por litro de diesel. Podendo, assim, concluir que o gasto com combustível de um caminhão é de $\mathrm{R} \$ 1,179$ por $\mathrm{km}$ rodado e sua economia de 7,8\% representa R\$ 0,1396 por quilômetro. Ainda se computou a economia tanto na ida quanto na volta do veículo, assim como também os cálculos com as demais variáveis a exemplo do gasto com o pedágio (Tabela 1). 
Tabela 1. Base para cálculo do consumo de combustível

\begin{tabular}{lcc}
\hline & Economia com Combustível \\
\hline Preço médio litro diesel & $\mathrm{R} \$ 3,30$ \\
Consumo médio km/L & 1,9 \\
Gasto por km & $\mathrm{R} \$ 1,79$ \\
Economia em \% por km & $7,8 \%$ \\
Economia real por km & $\mathrm{R} \$ 0,14$ \\
\hline
\end{tabular}

Fonte: Bartholomeu e Caixeta Filho (2008); Volvo e ANP (2016). Elaborada pelo autor.

Este trabalho utilizará desse percentual de economia de combustível para aplicar aos trechos estudados e assim mensurar os benefícios da concessão da BR-163.

\section{c) Economia com o custo operacional do veículo}

Controlar o custo operacional é importante para se definir a vida útil econômica do veículo. Assim, ao prolongar o tempo de operação de um veículo, seu custo operacional médio anual será minimizado.

Entende-se por custo operacional os custos de reposição de peças, os lubrificantes usados no motor, a reposição de pneus e, também, a graxa e a limpeza periódica do veículo. Os gastos com combustível que, nesta pesquisa, serão feitos por meio de um cálculo separado, são exceção.

A NTC\&Logística (2015) pesquisou o impacto do estado de conservação das rodovias pavimentadas sobre os custos operacionais dos caminhões, tomando-se como base um cavalo mecânico $4 \times 2$ tracionando carreta de três eixos. Concluiu-se que o custo operacional aumenta à medida que o estado de conservação da rodovia piora. A partir desta pesquisa formulou-se índice para mensurar o aumento do custo operacional relacionado à condição da rodovia.

De acordo com a pesquisa NTC\&Logística (2015),

O estado de conservação das rodovias tem sensível impacto sobre o custo operacional dos veículos [...], se o custo na rodovia ótima é 100, sobe para 119,4 na rodovia em bom estado, passando a 141 na rodovia regular, 166 na rodovia ruim, para atingir 191,6 na rodovia em estado de conservação péssimo (NTC, 2015, p. 89).

Para efetuar cálculo de economia do custo operacional dos veículos no transporte de soja na BR-163, em estrada em ótimo estado de conservação, utilizaremos como parâmetros os resultados encontrados dos estudos da CNT, a saber: para rodovia em estado de conservação ótimo não existe aumento, se estiver em bom estado o aumento será de $19,4 \%$, se regular, $41 \%$, ruim, 66\% e 91,6\% se estiver em péssimo estado de conservação (Tabela 2).

Para definir o custo de operacional por quilômetro rodado que serviu como balizador aos demais percentuais, ou seja, aquele valor que representa o custo operacional de uma rodovia em ótimo estado de conservação foi utilizado o simulador de custo de frete criado pela ANTT, que faz cálculo dos custos operacionais para veículos rodoviários de carga. Este simulador tem a finalidade de orientar as atividades de avaliação na escolha de transporte, na negociação e na contratação de fretes, especialmente, as atividades da Conab.

\section{d) Gastos com o valor de pedágio}

A cobrança de pedágios pela BR-163 tem gerado discussões quanto ao seu impacto econômico na economia local. Existe o temor de que o preço do pedágio encareça o custo final das mercadorias, especialmente

Tabela 2. Condição da rodovia e o custo operacional de caminhões

\begin{tabular}{ccc}
\hline Condição da rodovia - CNT & \multicolumn{2}{c}{ Custo Operacional por km } \\
\hline Ótima & $100 \%$ & $\mathrm{R} \$ 2,97$ \\
Boa & $119 \%$ & $\mathrm{R} \$ 3,53$ \\
Regular & $141 \%$ & $\mathrm{R} \$ 4,19$ \\
Ruim & $166 \%$ & $\mathrm{R} \$ 4,93$ \\
Péssima & $191 \%$ & $\mathrm{R} \$ 5,69$ \\
\hline
\end{tabular}

Fonte: NTC (2015). Elaborada pelo autor, por meio do simulador da ANTT. 
daquelas que têm pouco valor agregado. No caso específico da soja, quem absorve o custo do transporte é o produtor, visto que, mesmo nos casos em que o comprador se responsabiliza pelo transporte, ele acaba por pagar um valor inferior na saca em regióes distantes, como em Mato Grosso comparativamente às regiões como Paraná ou Rio Grande do Sul.

Segundo estudos da Secretaria de Transportes do Estado de São Paulo, a tarifa de pedágio corresponde a $8,6 \%$ do valor do frete. Isso no estado onde as concessões de rodovias incluem a obrigatoriedade da execução de obras de ampliação e melhorias, assim como o pagamento do ônus da concessão, cujos valores são aplicados na manutenção das rodovias secundárias (MITOS e FATOS, 2010).

As concessionárias defendem que as rodovias concedidas e conservadas com infraestrutura melhorada, tendem a diminuir os custos com o transporte, aumentando a eficiência do transporte e alavancando consideravelmente a competitividade de cada região (ABCR, 2016).

A cobrança de pedágio ocorre sobre a quantidade de eixos do veículo. Assim, os gastos com pedágios resultam da soma do valor cobrado nas praças de pedágios existentes em determinado trecho a ser percorrido, multiplicado pelo número de eixos do veículo utilizado (Tabela 3).

\section{Procedimentos metodológicos}

\subsection{Quantificação das perdas de grãos de soja}

Para quantificar os grãos de soja que se perdem pelo caminho em decorrência da qualidade da pavimentação da estrada, a pesquisa adotou dois parâmetros indicados pela Conab e CNT como critérios objetivos para quantificar os impactos decorrentes das condições da estrada (BR-163). Para tal, foram utilizados como base:

- A classificação das rodovias conforme dados da Confederação Nacional de Transporte que em sua pesquisa classifica o estado das estradas em: ótimo, bom, regular, ruim ou péssimo (CNT, 2014);

- O percentual das perdas de grãos em rodovias será estimado aqui, de acordo com a informação utilizada pela Conab, considerando que, devido à má conservação de pavimentação das rodovias, as perdas de soja variam de $0,2 \%$ a $0,6 \%$ da carga transportada (ORNAGHI, 2015).

A partir dessas informações, buscou-se um modelo que permitisse mensurar a perda da soja em rodovias. Entendendo que, em rodovias que apresentam péssimas condições de pavimentação, existe a maior perda

Tabela 3. Preços e praças dos pedágios na BR-163

\begin{tabular}{lccc}
\hline & Rota do Oeste - BR-163 Mato Grosso & \\
\hline \multicolumn{1}{c}{ Praça de Pedágio } & $\mathbf{1}$ eixo & Volta $-\mathbf{6}$ eixos & Ida - 9 eixos \\
\hline Itiquira & $\mathrm{R} \$ 4,00$ & $\mathrm{R} \$ 24,00$ & $\mathrm{R} \$ 36,00$ \\
Rondonópolis & $\mathrm{R} \$ 4,50$ & $\mathrm{R} \$ 27,00$ & $\mathrm{R} \$ 40,50$ \\
Campo Verde & $\mathrm{R} \$ 3,70$ & $\mathrm{R} \$ 22,20$ & $\mathrm{R} \$ 33,30$ \\
Santo Antônio de Leverger & $\mathrm{R} \$ 3,60$ & $\mathrm{R} \$ 21,60$ & $\mathrm{R} \$ 32,40$ \\
Jangada & $\mathrm{R} \$ 4,90$ & $\mathrm{R} \$ 29,40$ & $\mathrm{R} \$ 44,10$ \\
Diamantino & $\mathrm{R} \$ 4,10$ & $\mathrm{R} \$ 24,60$ & $\mathrm{R} \$ 36,90$ \\
Nova Mutum & $\mathrm{R} \$ 3,30$ & $\mathrm{R} \$ 19,80$ & $\mathrm{R} \$ 29,70$ \\
Lucas Rio Verde & $\mathrm{R} \$ 4,30$ & $\mathrm{R} \$ 25,80$ & $\mathrm{R} \$ 38,70$ \\
Sorriso & $\mathrm{R} \$ 6,10$ & $\mathrm{R} \$ 36,60$ & $\mathrm{R} \$ 54,90$ \\
Total & $\mathrm{R} \$ 38,50$ & $\mathrm{R} \$ 231,00$ & $\mathrm{R} \$ 346,50$ \\
Média KM & $\mathrm{R} \$ 0,045$ & $\mathrm{R} \$ 0,27$ & $\mathrm{R} \$ 0,41$ \\
\hline
\end{tabular}

Fonte: Rota do Oeste. Elaborada pelo autor. 
de grãos, nesse caso, de $0,6 \%$, e em rodovias ruins tem perda de $0,45 \%$ sendo regular corresponde a $0,30 \%$, boas, $0,15 \%$ e, e em rodovias em ótimo estado de conservação, as perdas de soja pelo caminho são desprezíveis, assemelhando-se a 0,00\%.

Considerou-se a distância média brasileira de transporte de grãos, de 900 a 1.000 km, para estimar os percentuais que são perdidos (TAVARES, 2004). Assim, para os cálculos, elegeu-se a estimativa média, de 1000 $\mathrm{km}$ de distância. A partir da estimativa de (i) distância percorrida, aliada ao (ii) percentual de perdas de grãos da Conab; (iii) o estado de conservação da pavimentação (classificação da CNT), obteve-se subsídios para elaborar uma classificação para inferir que:

Índice de perdas $=$ (Distância $\times$ estado do pavimento da rodovia)

Sendo perdas:

Perdas $=($ Quantidade transportada $\times$ índice de perdas)

\subsection{Quantificação das variáveis econômicas}

Para mensurar monetariamente os custos e benefícios da BR-163 pedagiada, elegeu-se, como modelo para simular uma rota de escoamento, um caminhão da marca Volvo FH 540, carroceria Bitrem, de nove eixos, com capacidade de lotação de 48 toneladas.

\subsubsection{Economia com menor perda da soja}

Utilizou-se o resultado do índice de perdas de soja conforme item 3.2 da metodologia, considerando-se a capacidade de carga do caminhão de 48 toneladas.

Conforme essa metodologia, o percentual de perda de soja está intrinsicamente ligada às condições da pavimentação das rodovias indicadas pela Conab (2004). A CNT pesquisou a qualidade da pavimentação da BR-163 em 2013 (CNT, 2014). De acordo com o levantamento, a pavimentação nos estados de Mato Grosso e Mato Grosso do Sul estava em diferentes condições de rodagem.

Nesta pesquisa, para averiguar a perda e, assim, quantificar monetariamente a economia, foi feita uma simulação com caminhão de 48 toneladas estimando o percentual de perdas, conforme as condições da pavimentação da rodovia em MT e MS, informados pela CNT (2014). A partir do cálculo da quantidade que fica pelo caminho, computou-se o valor perdido pelo preço médio da saca de soja, sendo em Mato Grosso de $\mathrm{R} \$ 60,00$, e o preço médio, em MS, de R\$ 65,00, conforme cotação de fevereiro de 2016 e considerando o mesmo período para a cotação e pedágio.

\subsubsection{Economia com o consumo de combustível}

Para calcular a economia com combustível, contribuíram os estudos de Bartholomeu e Caixeta Filho (2008), que mensuraram economia de combustível de caminhões em estradas, com condições de conservação distintas. Concluíram, em suas análises, classificadas por eles, que em "rodovia melhor conservada" houve economia de $7,8 \%$ no consumo de combustível, comparativamente a rodovias em que o estado de conservação da pavimentação estava piorado.

Utilizou-se esse percentual de resultado para mensurar a economia com combustível em distâncias específicas pela BR-163, fazendo o cálculo por quilômetro rodado. Para isso, buscou-se o preço médio do diesel em Mato Grosso e Mato Grosso do Sul em fevereiro de 2016, sendo de R\$ 3,30 por litro, considerou-se o rendimento médio do caminhão Volvo FH 540, que é $1,9 \mathrm{~km}$ com litro de diesel. Assim, foi possível concluir que o gasto com combustível de um caminhão é de $\mathrm{R} \$ 1,179$ por $\mathrm{km}$ rodado e sua economia de $7,8 \%$ representa R\$ 0,1396 por quilômetro. A partir destes dados, computou-se a economia tanto na ida quanto na volta do veículo, estimando também os cálculos com as demais variáveis, a exemplo do gasto com o pedágio.

\subsubsection{Economia com o custo operacional do veículo}

A NTC\&Logística (2015) avaliou o custo operacional de caminhões de carga que trafegam em rodovias de qualidades de pavimentação diversas. Para efetuar cálculo de economia do custo operacional do veículo no transporte de soja na BR-163 foram apropriados os resultados encontrados pela pesquisa da NTC\&Logística. Considerando-se que a rodovia em ótimo estado de conservação é a base do cálculo, logo, não existe aumento; no entanto, se estiver em bom estado, o aumento é de 19,4\%, se regular, 41\%, ruim, $66 \%$ e $91,6 \%$ se estiver em péssimo estado de conservação. 
Diferente da pesquisa NTC\&Logística, que utilizou um caminhão de médio porte em sua pesquisa, aqui o caminhão adotado é de carga pesada, Volvo FH 40; sendo assim, o valor do custo operacional tende a ser diferente, em razão do modelo do caminhão e da atualização do preço das variáveis que compõem o custo operacional.

O parâmetro adotado para calcular o custo de manutenção deste caminhão foi a planilha de custo da Agência Nacional de Transportes Terrestres (ANTT). Assim, elegeu-se o valor base do custo operacional de $\mathrm{R} \$ 2,97$ por $\mathrm{km}$, desprezando o gasto com combustível, já que representa um cálculo à parte nesta pesquisa.

\subsubsection{Gastos com o pedágio}

O gasto com pedágio compõe o custo geral do transporte de soja, escoado pela BR-163. A cobrança teve início no final de setembro de 2015 pelas concessionárias Rota do Oeste, no estado de Mato Grosso e CCR MSVia, em Mato Grosso do Sul.

Neste estudo, o custo total com o pedágio foi elencado como o resultado da soma dos preços das praças em determinado trecho, considerando-se a quantidade de eixos do caminhão. A estimativa levou em consideração o trajeto "ida e de volta" do veículo. Ao utilizar um caminhão Volvo FH 40, bitrem de 9 eixos, o pedágio é cobrado pela totalidade dos eixos e, na volta, cobra-se somente por seis eixos, em razão de que, ao retornar, três eixos regressam suspensos. $\mathrm{O}$ estudo não considerou a possibilidade de carga no retorno, ou seja, desconsidera-se a possibilidade de o caminhão retornar com nova carga.

\subsection{Definição das rotas da soja pela $B R-163$}

As rotas percorridas para o escoamento da soja via BR163 foram definidas privilegiando caminhos que escoam a produção para exportação. A intenção foi verificar, quantitativamente, as perdas dos grãos de soja em determinados percursos intermediários, trechos e distância percorrida nos estados de MS e MT.

Para definir os pares, origem - destino buscou-se elencar os principais municípios em que se concentra o setor produtivo de soja nos estados de Mato Grosso e de Mato Grosso do Sul. Para isso, fez-se levantamento da produção de soja dos municípios que estão localizados nos referidos estados através do IBGE cidades, e assim, elencaram-se os municípios originários do transporte da soja, considerados aqueles que têm percurso obrigatório pela BR-163. Já o destino final são os portos aos quais se propõem a transportar a soja.

Dados da Aliceweb permitiram identificar os referidos portos e a quantidade exportada (BRASIL, 2015). A Empresa de Planejamento e Logística (EPL) mapeou o fluxo da demanda agrícola a granel, em 2015, tanto no estado de Mato Grosso quanto no estado de Mato Grosso do Sul, e evidenciou a colossal utilização da BR-163 no escoamento da produção aos portos (EPL, 2015).

O percurso intermediário se inicia e termina na BR-163. Portanto, a rota intermediária limita-se à quilometragem compreendida entre o ponto em que o caminhão entra na BR-163 e o ponto em que sai dela. $\mathrm{Na}$ Tabela 6, foram elencados oito trechos para levantar o que se perde de soja em tonelada pela BR-163, recorte por percurso, referente ao transporte da safra de 2014 destinada à exportação. Nessa tabela não foram computados os valores monetários das perdas, caracterizando, exclusivamente, a quantidade de soja em toneladas que fica pela rodovia.

Já na Tabela 7, para analisar monetariamente os custos com o pedágio e confrontá-los aos benefícios econômicos advindos de uma rodovia em condição ótima de pavimentação, foram elencadas algumas variáveis que representaram os benefícios econômicos, como a economia com "desperdício" da soja, a economia com combustível e a economia com o custo operacional do caminhão transportador.

\section{Análise e apresentação dos resultados}

A BR-163 corta o País de Norte a Sul e abrange os estados do Pará, passando por Mato Grosso, Mato Grosso do Sul, Paraná, Santa Catarina e Rio Grande do Sul. Torna-se, assim, uma das principais rodovias de escoamento de grãos na região da fronteira agrícola do Brasil. Contudo, a BR-163 tem se mostrado insuficiente para atender à demanda que é crescente, agravada pela falta de conservação e deterioração de sua malha viária, como demostra a Tabela 4, a seguir.

Em levantamento sobre a conservação da rodovia BR 163, realizado pela Confederação Nacional de Transporte (CNT), no estado de Mato Grosso foram identificados problemas de conservação ao longo de 
Tabela 4. Condições da rodovia BR-163 antes da concessão

\begin{tabular}{lccccc}
\hline \multicolumn{1}{c}{ Estado } & $\begin{array}{c}\text { Extensão } \\
\text { Pesquisada-km }\end{array}$ & Geral & Pavimento & Sinalização & Geometria \\
\hline Santa Catarina & 60 & Ruim & Ruim & Regular & Péssimo \\
Paraná & 357 & Regular & Regular & Regular & Ruim \\
Mato Grosso do Sul & 845 & Regular & Bom & Regular & Regular \\
Mato Grosso & 1.120 & Regular & Regular & Regular & Regular \\
Pará & 178 & Regular & Bom & Regular & Ruim \\
Brasil & 2.560 & Regular & Regular & Regular & Regular \\
\hline
\end{tabular}

Fonte: Pesquisa CNT de rodovias 2014. Elaborada pelo autor.

toda a sua extensão de 1.120 quilômetros e, ainda, o estudo apontou alguns pontos críticos como erosão na pista, buracos grandes, pistas insuficientes e com sinalização precária. A CNT emitiu parecer que a classificou como uma estrada regular (CNT, 2014).

Essas distâncias aumentam demasiadamente o custo de escoamento desse produto. Assim, de maneira geral, os municípios produtores localizados no estado de Mato Grosso percorrem, em média, $2.000 \mathrm{~km}$ até alcançarem um porto para escoar seus produtos ao mercado internacional (CORREA e RAMOS, 2010).

O ministério do transporte considera a BR-163 como essencial para melhorar o desempenho da logística do setor agrícola, já que ela liga o Norte do País, desde o estado do Pará, aos estados produtores agrícolas como Mato Grosso, Mato Grosso do Sul (região
Centro-Oeste) e à região Sul, onde estão localizados os estados do Paraná, Santa Catarina e Rio Grande do Sul.

Contudo, até 2013 suas condições eram classificadas como regulares e insuficientes e, em determinados trechos, foi considerada como ruim e péssima pela pesquisa da Confederação Nacional do Transporte (CNT, 2014). Desse modo, elementos externos à produção geram transtornos aos produtores e impactam na competitividade do produto primário no mercado externo, principalmente porque elevam os custos do escoamento dos grãos, dentre eles a soja, e atingem a rentabilidade e a eficiência de toda a cadeia produtiva (CORREA e RAMOS, 2010; OJIMA e YAMAKAMI, 2006).

A Figura 2, elaborado pela Empresa de Planejamento e Logística (EPL) demonstra o fluxo da

Figura 2. Demanda do granel sólido agrícola sobre o Modal Rodoviário brasileiro (2015)

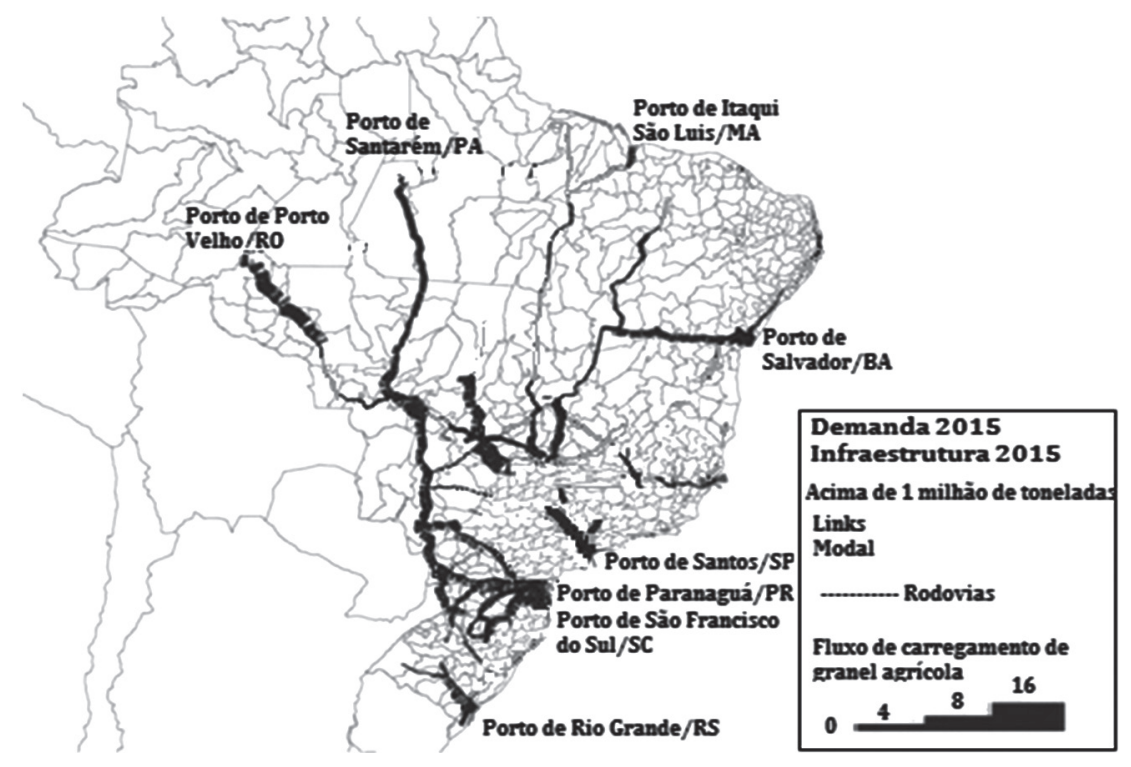

Fonte: Empresa de Planejamento e Logística (EPL), adaptada pelos autores. 
demanda agrícola a granel, em 2015, e as principais vias brasileiras para escoamento da produção. É notória a imensa utilização da BR-163 no estado de Mato Grosso e ainda fica explicitada a sua contribuição para a economia agrícola nacional (EPL, 2015).

Em período anterior à concessão, a estrada encontrava-se deteriorada e com pista de rolamento insuficiente para comportar a demanda e a sua função inicial de rodovia integradora das regiões Norte e Centro-Oeste aos demais estados do País (CNT, 2014). Apesar da essencialidade, como demostra o mapa exposto na Figura 2, havia a urgência de novos investimentos em pavimentação e ampliação, diante da constante elevação do fluxo de transporte agrícola.

Embora não exista um consenso sobre o valor exato dos prejuízos nos transportes de grãos, existe consenso sobre as suas principais causas, que se apresentam na forma em que são condicionados os produtos e, principalmente, na má conservação das rodovias brasileiras.

Para Correa e Ramos (2010), a precariedade da conservação da malha viária, aliada às longas distâncias percorridas para o escoamento da produção até os portos de Santos (SP), Paranaguá (PR), São Francisco do Sul (SC) e Santarém (PA) acabam comprometendo, em média, 25\% de receita referente à produção de soja, são prejuízos do processo de escoamento, devido aos altos custos internos de transportes.

A soja, considerada uma das mais importantes commodities brasileiras, possui um dos maiores problemas logísticos entre as cadeias produtivas do País, principalmente no que se refere à armazenagem e ao transporte. Assim, uma grande parte da produção é perdida por falta de área de armazenagem e más condições de transporte, que envolvem frota envelhecida de caminhões, estradas em péssimas condições e grandes distâncias de deslocamentos.

Segundo pesquisa da Associação Brasileira de Agribusiness (Abag), o Brasil perde cerca de 6\% de sua produção de grãos durante o transporte das safras até os mercados de destino (ORNAGHI, 2015). Ao considerarmos a safra de soja 2014/2015, que foi de 96 milhões de toneladas, este percentual equivaleria a 5,8 milhões de toneladas. A Central de Comercialização de Grãos, da Federação da Agricultura e Pecuária de Mato Grosso (Famato), calculou que a perda de grãos no estado de Mato Grosso gera prejuízo anual de R\$ 21 milhões (BORGES et al., 2013). Em pesquisa apresentada pela Cargil Alimentos, em rodovias de Mato Grosso, se perde $0,30 \%$ da carga de grãos, enquanto em rodovias bem conservadas este índice não ultrapassou 0,08\% (BRASIL, 2016).

Kussano e Batalha (2012) afirmam que a perda de grãos pelo caminho representa, em média, $0,25 \%$ do produto movimentado e que este problema atinge a quase todas as regiões produtoras do País, agravando-se em locais mais distantes, como o caso dos estados de Mato Grosso, por percorrerem distâncias superiores a mil quilômetros, em estradas precárias. $\mathrm{O}$ acondicionamento inadequado durante o transporte também é indicado pelo Semprebom (2009), como um dos fatores que contribuem para a perda dos grãos.

A Companhia Nacional de Abastecimento (Conab) utiliza como parâmetro de comparação sobre o que se perde no transporte dos grãos, um índice que varia entre $0,2 \%$ a $0,6 \%$ da carga, considerado como aceitável para perdas de grãos durante o seu transporte (ORNAGHI, 2015). Semelhante à Aprosoja (2016) que também estimou perdas médias de $0,25 \%$ dos grãos em transporte rodoviário.

Ainda, o fator distância aparece na pesquisa da Conab (2004) como fator crítico à competitividade da soja, visto que a concentração de produtores e do setor produtivo brasileiro de soja está a uma distância média de 900 a $1.000 \mathrm{~km}$ dos portos brasileiros, semelhante aos percursos estadunidenses, com distância média de $1.000 \mathrm{~km}$ (TAVARES, 2004).

Para calcular o índice de soja pelo que cai pelo caminho, observam-se a distância percorrida na rota e a classificação das condições da rodovia, considerando a avaliação realizada pela CNT. Para mensurar o total perdido utilizou-se a equação de multiplicar a quantidade de soja transportada pelo índice que classifica a conservação da rodovia como ótimo, bom, regular, ruim e péssimo, conforme índices expostos na Tabela 5 : 
Tabela 5. Percentual de perda de soja conforme condições das rodovias

\begin{tabular}{lccccccccccc}
\hline Pavimento/KM & $\mathbf{1 0 0 0}$ & $\mathbf{9 0 0}$ & $\mathbf{8 0 0}$ & $\mathbf{7 0 0}$ & $\mathbf{6 0 0}$ & $\mathbf{5 0 0}$ & $\mathbf{4 0 0}$ & $\mathbf{3 0 0}$ & $\mathbf{2 0 0}$ & $\mathbf{1 0 0}$ & $\mathbf{1}$ \\
\hline Ótimo & $0,00 \%$ & $0,00 \%$ & $0,00 \%$ & $0,00 \%$ & $0,00 \%$ & $0,00 \%$ & $0,00 \%$ & $0,00 \%$ & $0,00 \%$ & $0,00 \%$ & $0,00 \%$ \\
Bom & $0,15 \%$ & $0,14 \%$ & $0,12 \%$ & $0,11 \%$ & $0,09 \%$ & $0,08 \%$ & $0,06 \%$ & $0,05 \%$ & $0,03 \%$ & $0,02 \%$ & $0,00015 \%$ \\
Regular & $0,30 \%$ & $0,27 \%$ & $0,24 \%$ & $0,21 \%$ & $0,18 \%$ & $0,15 \%$ & $0,12 \%$ & $0,09 \%$ & $0,06 \%$ & $0,03 \%$ & $0,00030 \%$ \\
Ruim & $0,45 \%$ & $0,41 \%$ & $0,36 \%$ & $0,32 \%$ & $0,27 \%$ & $0,23 \%$ & $0,18 \%$ & $0,14 \%$ & $0,09 \%$ & $0,05 \%$ & $0,00045 \%$ \\
Péssimo & $0,60 \%$ & $0,54 \%$ & $0,48 \%$ & $0,42 \%$ & $0,36 \%$ & $0,30 \%$ & $0,24 \%$ & $0,18 \%$ & $0,12 \%$ & $0,06 \%$ & $0,00060 \%$ \\
\hline
\end{tabular}

Fonte: Pesquisa CNT de rodovias (2014), Ornaghi (2015). Elaborada pelo autor.

A Tabela 5 caracteriza a ponderação do percentual de perda dos grãos de soja transportado pela BR-163, nos estados de Mato Grosso, em período anterior à concessão da rodovia. De acordo com a ponderação, a BR-163 no percurso circunscrito ao estado de Mato Grosso, considerando os indicadores da CNT (2014) de pavimentação regular, perde-se $0,3 \%$ de seus grãos pela rodovia a cada $1.000 \mathrm{~km}$. Espera-se, com os novos investimentos na rodovia, esse índice se aproxime de zero.

Como visto, o estado de Mato Grosso transporta sua safra agrícola por trajetos longos, encontra-se a $2.000 \mathrm{~km}$ de distância dos portos e em estradas com condições com pouca estrutura. No caso do escoamento da produção de soja de MT, os prejuízos são alavancados pelas condições da pavimentação da rodovia. O custo do transporte destes estados acaba agregando ao valor final da soja, desdobram-se por vezes em diminuir o valor da saca da soja.

A Tabela 6 se refere à simulação da quantidade perdida de soja, utilizando-se do índice de perdas da Tabela 5. A intenção de verificar quantitativamente as perdas a partir dos percursos intermediários, trechos e distância percorrida durante a safra de soja de 2014 .

Percebe-se, portanto, que a soja procedente do município de Sorriso (MT), que tem como rota a BR-163 e percorre $600 \mathrm{~km}$ por ela até a cidade de Rondonópolis, onde um complexo multimodal interliga os modais ferroviário e rodoviário; a partir daí a soja segue de trem até o porto de Santos, que é o destino final pretendido.

No trecho compreendido entre Sorriso e Rondonópolis, ambas em MT, calcula-se que se tenham

Tabela 6. Perda de soja em tonelada pela BR-163, recorte por município, safra de 2014

\begin{tabular}{|c|c|c|c|c|c|c|c|c|}
\hline $\begin{array}{l}\text { Município expor- } \\
\text { tador }\end{array}$ & $\begin{array}{l}\text { Percurso inter- } \\
\text { mediário } \\
\text { Entrada e saída } \\
\text { da BR-163 }\end{array}$ & $\begin{array}{c}\text { Trecho BR- } \\
\text { 163/MT }\end{array}$ & $\begin{array}{c}\text { Trecho BR } \\
\text { 163/MS }\end{array}$ & $\begin{array}{c}\text { Distância total } \\
\text { BR-163 }\end{array}$ & $\begin{array}{l}\text { Quant./ton. } \\
\text { Exportada }\end{array}$ & $\%$ Exp. & $\begin{array}{c}\text { Desperdício } \\
\text { grãos/ton. Pela } \\
\text { BR-163 }\end{array}$ & Destino final \\
\hline \multirow{2}{*}{ Sorriso/MT } & $\begin{array}{l}\text { Sorriso - Ron- } \\
\text { donópolis }\end{array}$ & $600 \mathrm{~km}$ & - & $600 \mathrm{~km}$ & 713.320 & $70 \%$ & 1.284 & Porto de Santos \\
\hline & $\begin{array}{l}\text { Sorriso - Nova } \\
\text { Alvorada do Sul }\end{array}$ & $760 \mathrm{~km}$ & $440 \mathrm{~km}$ & $1200 \mathrm{~km}$ & 305.709 & $30 \%$ & 899 & $\begin{array}{c}\text { Porto de } \\
\text { Paranaguá }\end{array}$ \\
\hline \multirow[b]{2}{*}{ Nova Mutum/MT } & $\begin{array}{l}\text { Nova Mutum - } \\
\text { Rondonópolis }\end{array}$ & $450 \mathrm{~km}$ & - & $450 \mathrm{~km}$ & 548.624 & $89 \%$ & 988 & Porto de Santos \\
\hline & $\begin{array}{l}\text { Nova Mutum - } \\
\text { Nova Alvorada } \\
\text { do Sul }\end{array}$ & $610 \mathrm{~km}$ & $440 \mathrm{~km}$ & $1050 \mathrm{~km}$ & 67.808 & $11 \%$ & 167 & $\begin{array}{c}\text { Porto de } \\
\text { Paranaguá }\end{array}$ \\
\hline \multirow[b]{2}{*}{ Diamantino/MT } & $\begin{array}{l}\text { Diamantino - } \\
\text { Rondonópolis }\end{array}$ & $360 \mathrm{~km}$ & - & $400 \mathrm{~km}$ & $266+467$ & $90 \%$ & 288 & Porto de Santos \\
\hline & $\begin{array}{l}\text { Diamantino - } \\
\text { Nova Alvorada } \\
\text { do Sul }\end{array}$ & $520 \mathrm{~km}$ & $440 \mathrm{~km}$ & $960 \mathrm{~km}$ & 29.607 & $10 \%$ & 66 & $\begin{array}{c}\text { Porto de } \\
\text { Paranaguá }\end{array}$ \\
\hline \multirow{2}{*}{$\begin{array}{l}\text { Lucas do Rio } \\
\text { Verde/MT }\end{array}$} & $\begin{array}{l}\text { Lucas do Rio } \\
\text { Verde - Rondo- } \\
\text { nópolis }\end{array}$ & $545 \mathrm{~km}$ & - & 545 & 282.628 & $89 \%$ & 462 & Porto de Santos \\
\hline & $\begin{array}{l}\text { Lucas do Rio } \\
\text { Verde - Nova } \\
\text { Alvorada do Sul }\end{array}$ & $700 \mathrm{~km}$ & $440 \mathrm{~km}$ & 1.145 & 31.756 & $10 \%$ & 88 & $\begin{array}{c}\text { Porto de } \\
\text { Paranaguá }\end{array}$ \\
\hline
\end{tabular}

Fonte: Elaborada pelo autor. 
perdido 1.284 toneladas de grãos de soja em 20147. Esse quantitativo é resultado da relação entre a distância percorrida na BR-163 e o índice ponderado do percentual daquilo que se perde de soja, conforme Tabela 6. Nesse caso, $600 \mathrm{~km}$ correspondem a 0,18\% de prejuízo da quantidade transportada em estradas em que seu pavimento esteja em condições regulares, conforme Tabela 6.

Ao analisar outro percurso, entre Sorriso (MT) e Nova Alvorada do Sul (MS), pondera-se a distância percorrida na BR-163, em Mato Grosso, e o índice de perdas relativo à condição da pavimentação da rodovia, nesse caso, para $760 \mathrm{~km}$, o índice correspondente em estrada de condições regulares será de $0,228 \%$ de perdas da carga. Da mesma maneira se fará o cálculo para o percurso no estado de Mato Grosso do Sul. Sendo um trecho de $440 \mathrm{~km}$, o índice correspondente será de $0,066 \%$ de perda da soja pelo caminho, que totaliza a quantidade de 899 toneladas de grãos perdidos, somente entre aquelas que se destinaram à exportação pelo porto de Paranaguá em 2014.

Adiante, confrontou-se o custo de uma rodovia pedagiada com os benefícios de uma estrada em condições ótimas, as perdas da soja em grãos serão mensuradas juntamente com os demais benefícios, como a economia de combustível e redução de gastos na manutenção do veículo. De maneira hipotética, o caso de um caminhão Volvo FH 540, carroceria Bitrem, de nove eixos, com capacidade de lotação de 48 toneladas.

Para mensurar as variáveis econômicas, consideraram-se os trechos de transporte rodoviários de soja que perpassam pela BR-163. Caminhos mais frequentes e que intermediam o setor produtivo e os portos. A Tabela 7 apresenta a comparação entre o custo com o pedágio e as economias propiciadas pela rodovia em ótimas condições de trafegabilidade.

Os resultados apresentados pela Tabela 7 evidenciaram o custo que se tem com pedágio em determinados trechos e, ao mesmo tempo, contrapuseram esses custos com a economia propiciada por trafegar em uma rodovia em ótimas condições de pavimentação.

A exemplo no primeiro trecho que liga a cidade de Sorriso (MT) a Rondonópolis (MT). Sorriso é a origem

7. Esse quantitativo de perdas de soja representa somente aquelas que se destinaram à exportação. Aqui não está considerado o que se perde de toda a produção de soja dos municípios, incluindo a que é transportada para as empresas esmagadoras. da rota, está localizada à margem da BR-163, sendo um importante produtor de soja; e Rondonópolis é o destino da rota, pois tem uma estação ferroviária pela qual escoa a produção de soja em direção ao porto de Santos.

Essa rota possui $600 \mathrm{~km}$, em que se gasta com pedágios $R \$ 426,00$, sendo $R$ \$ 255,60 na ida e $R \$ 170,40$ na volta, num total de sete praças de pedágios explicitados no Apêndice A. Em compensação a esse gasto foram computadas as economias de $\mathrm{R} \$ 86,00$ propiciadas com a menor perda de soja (trecho somente em MT), mais a economia com gasto com combustível no valor de R\$167,54 e somando, ainda, a economia com o custo operacional do caminhão no valor de $\mathrm{R} \$ 730,62$, totalizando economia de R\$984,56. Ao contrapor o gasto com pedágio às economias alcançadas, o resultado apresentado foi ganho das economias em $\mathrm{R} \$ 558,56$.

Ao se repetir este cálculo nas demais rotas pela BR-163 com origem no estado de Mato Grosso, em todos os trechos apresentados de ida e volta, os ganhos econômicos superaram os gastos com pedágios em percentuais acima de $130 \%$.

E ainda se considerou a análise das variáveis econômicas em todo o trecho que abarca a concessão no estado de Mato Grosso (trecho 9). Para percorrer os 850 $\mathrm{km}$ de estrada se gasta $\mathrm{R} \$ 577,50$ com pedágio, somados gastos de ida e de volta. No entanto, com economia da soma das três variáveis, o ganho é de $\mathrm{R} \$ 1.396,28$, sendo que o resultado totalizou ganho de $\mathrm{R} \$ 818,78$, ou seja, a economia superou os custos com pedágio em $142 \%$.

É importante observar que as perdas de grãos de sojas compreendem somente ao trecho de ida do caminhão, para todos os percursos calculados na Tabela 7. No entanto, nos percursos que têm como destino a cidade de Nova Alvorada do Sul (MS), o caminhão percorrerá os dois estados. Ocorre que a qualidade da pavimentação asfáltica é diferente entre eles, o que gera dois índices de perdas de grãos, perceptíveis nos trechos de 5 a 8 .

Ao considerar a participação de cada variável no custo do pedágio na BR-163 em Mato Grosso, a economia com o prejuízo de perdas de soja representa $21 \%$, a economia com o combustível representou $41 \%$ e a economia com o custo operacional, $179 \%$. Neste caso, percebe-se que somente a economia que se tem com o custo operacional do caminhão será suficiente para 


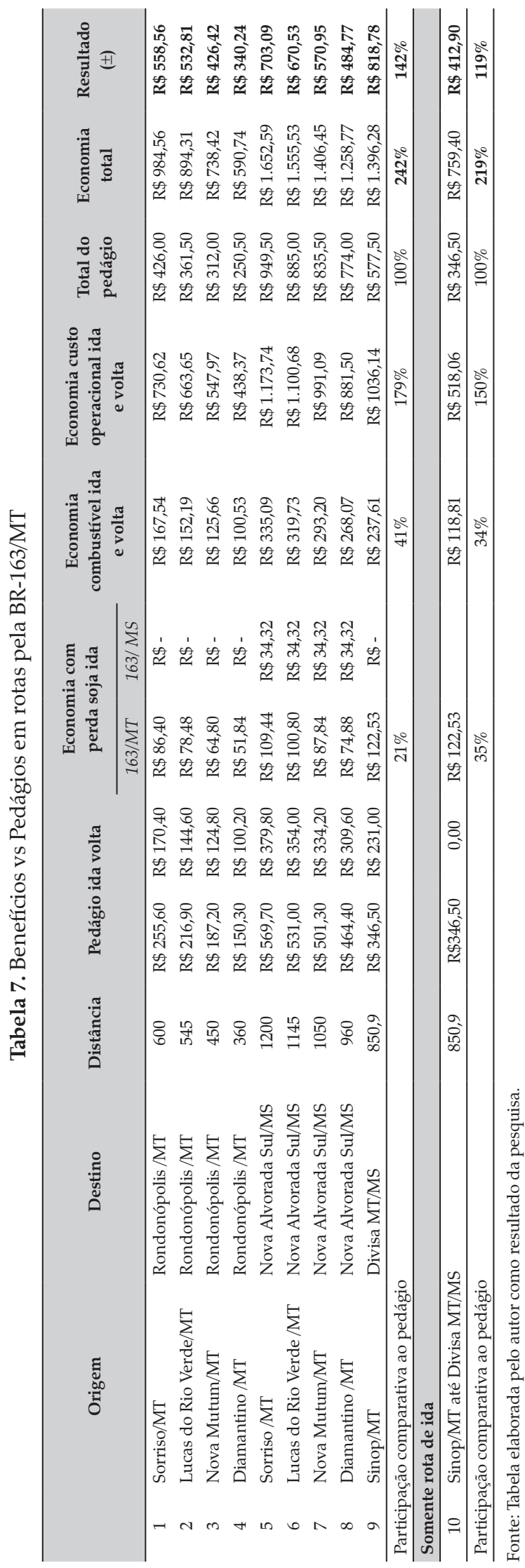


pagar o gasto com o pedágio. Mesmo desprezando, a possibilidade de carga de retorno.

Pode-se também avaliar, no trecho 9, somente a rota da ida dos caminhões no transporte de soja. Se gasta com pedágio $\mathrm{R} \$ 346,50$ para percorrer os $850 \mathrm{~km}$ pela BR-163; em contrapartida, as economias proporcionadas pelas três variáveis analisadas superariam somam-se $\mathrm{R} \$ 759,40$, relação que aponta que, a cada $100 \%$ gastos com pedágio, há um ganho de $219 \%$, ou seja, o ganho supera o custo com pedágio em $119 \%$.

Tornou-se evidente nesta análise que a concessão da BR-163 trará maior competitividade aos transportadores de soja no estado de Mato Grosso.

\section{Considerações finais}

A transferência de serviços públicos da BR-163 para a administração privada foi motivada pela necessidade emergencial de recuperação da pavimentação asfáltica e ampliação da malha rodoviária. O Estado buscou nos mecanismos de mercado medidas concretas de gestão, de eficiência na manutenção e, principalmente de autofinanciamento da infraestrutura.

Este trabalho mensurou, através da análise da concessão da BR-163, quais seriam as implicações originadas pela rodovia concedida à administração privada e, consequentemente, pedagiada, para a competitividade do setor da soja do estado de Mato Grosso.

Considerando as distâncias, os custos com pedágio e os benefícios advindos da rodagem em rodovias ditas de "qualidade" a partir da eleição de rotas pré-estabelecidas, o estudo identificou que nas rotas elencadas no estado de Mato Grosso ocorrem ganhos econômicos na marca acima de 119\%, num comparativo com os custos com pedágios.

Os resultados encontrados auxiliaram na resposta a questões norteadoras deste trabalho, como: "é possível ganhar competitividade em rodovia pedagiada?" Sim, é possível alcançar maior desempenho competitivo em rodovias pedagiadas, especialmente porque a pesquisa aponta ganhos econômicos que superaram o custo do pedágio.

Porém, isso está amplamente relacionado às condições da rodovia em período anterior a sua concessão, a BR-163 no estado de Mato Grosso, que estava arruinada ao que a pesquisa CNT (2014) a classificou com a pavimentação regular, o que aumentava consideravelmente o custo do transporte da soja. Assim, após a concessão, ao trafegar em estrada de pavimentação ótima, alcançaria economia com "desperdício" de soja em 0,03\% do volume transportado a cada $100 \mathrm{~km}$ rodado. E pelo mesmo motivo, também teria maior economia com o custo operacional do caminhão que, de acordo com a NTC\&logística, seria de $41 \%$.

Por fim, o resultado da pesquisa aponta que os ganhos econômicos e as implicações para o setor da soja, a partir da concessão de rodovias, são relativos, especialmente porque podem representar maior ou menor ganho, dependendo, inclusive, das condições anteriores de conservação da rodovia. Sugere-se como trabalhos futuros a mesma análise, mas para todos os estados que sejam contemplados pela BR-163.

\section{Referências}

ABCR. Associação Brasileira dos Concessionários de Rodovias. Disponível em: <http:/www.abcr.org.br/ HistoriaABCR.aspx>. Acesso em: 20 jan. 2016.

. Pedágios: mitos e fatos. Revista e atualizada. 3. ed. São Paulo: Editora CLA, 2010.

ANTT - Agência Nacional de Transportes Terrestres. Disponível em: <http://www.antt.gov.br/>. Acesso em: 18 set. 2015 .

APROSOJA. Associação dos Produtores de Soja e Milho. Disponível em: <http://www.aprosoja.com. br/>. Acesso em: 10 fev. 2016.

BARTHOLOMEU, D. B. Quantificação dos impactos econômicos e ambientais decorrentes do estado de conservação das rodovias brasileiras. Tese (Doutorado) - Escola Superior de Agricultura Luiz de Queiroz, Universidade de São Paulo, Piracicaba, 2006.

BARTHOLOMEU, D. B. e CAIXETA FILHO, J. V. Impactos econômicos e ambientais decorrentes do estado de conservação das rodovias brasileiras: um estudo de caso. Rev. Econ. Sociol. Rural, v. 46, n. 3, Brasília, jul./set. 2008.

BORGES, G. R., ARAÚJO, F. e SOLON, A. S. Desperdício de Soja nas Estradas: análise de perdas de soja nas regiões sudeste e centro-oeste. XXXIII Encontro Nacional de Engenharia de Produção, 08 a 11 de outubro de 2013, Salvador, 2013.

BRASIL. Ministério de Desenvolvimento, Indústria e Comércio Exterior (MDIC). Sistema de Análise das Informações de Comércio Exterior, Secretaria de Comércio 
Exterior - AliceWeb. Disponível em: <http://www. aliceweb2.mdic.gov.br/>. Acesso em: 15 jul. 2015.

Portal da Câmara dos Deputados. Lona em caminhão de grãos pode ser obrigatória. Câmara Notícias, 2008. Disponível em: <http://www2.camara.leg.br/ camaranoticias/noticias/AGROPECUARIA/126351LONA-EM-CAMINHAO-DE-GRAOS-PODE-SEROBRIGATORIA.html>. Acesso em: 04 dez. 2016.

CAIXETA FILHO, J. V. Custo de Transporte no Agronegócio Brasileiro. Seminário CNI-BID. Transporte para o comércio e a integração regional. Brasília, 2008.

CAIXETA FILHO, J. V. e MARTINS, R. S. Gestão logística do transporte de cargas. São Paulo: Atlas, 2011.

CCR MSVia. Site institucional. Disponível em: < http:// www.grupoccr.com.br>. Acesso em: 29 nov. 2015.

CNT - Confederação Nacional de Transporte. Boletim Estatístico. Brasília, jul. 2007.

Boletim Estatístico. Brasília, jul. 2014.

Pesquisa CNT de rodovias 2014: relatório gerencial. Brasília, 2014.

Pesquisa CNT de rodovias 2015: relatório gerencial. Brasília, 2015.

CONAB - Companhia Nacional de Abastecimento. Corredores de Escoamento da Produção Agrícola: corredor da BR 163. Brasília, 2007.

. Acompanhamento de safra brasileira: grãos. Vol. 2, Safra 2014/15, n. 9. Nono Levantamento Junho, Brasília, 2015.

CORREA JR., G. M. Principais determinantes do preço do frete rodoviário para transporte de soja em grãos em diferentes regiões brasileiras: uma análise econométrica. Dissertação (Mestrado) - Economia Aplicada - Escola Superior de Agricultura Luiz de Queiroz, Universidade de São Paulo. Piracicaba, 2001.

e CAIXETA FILHO, J. V. Principais determinantes do preço do frete rodoviário para o transporte de soja em grãos em diferentes estados brasileiros: uma análise econométrica. Economia Aplicada, ano 7, v. 1, p. 189-211, jan./mar. 2003.

CORREA, V. H. C. e RAMOS, P. A precariedade do Transporte Rodoviário Brasileiro para o Escoamento da Produção de Soja do Centro-Oeste: situação e perspectivas. Rev. Economia e Sociologia Rural, Brasília, v. 48 , n. 2, abr./jun. 2010.

DI PIETRO, M. S. Z. Direito administrativo. 26. ed. São Paulo: Editora Atlas, 2014.
EPL. Empresa de Planejamento Logístico. Mapa do carregamento atual do modo de transporte rodoviário. Disponível em: <http://www.epl.gov.br/planonacional-de-logistica-integrada-pnli $>$. Acesso em: 12 dez. 2015.

FAMASUL, Federação da Agricultura e Pecuária de Mato Grosso do Sul. Disponível em: < http://famasul. com.br/>. Acesso em: 14 dez. 2015.

FLEURY, P. F. A infra-estrutura e os desafios logísticos das exportações brasileiras. Centro de Estudos em Logísticas (CEL), Instituto COPPEAD de Administração, Universidade Federal do Rio de Janeiro (UFRJ). Rio de Janeiro, 2005.

. Os gargalos da infraestrutura logística no Brasil. Economia Brasileira na Encruzilhada. Rio de Janeiro: Editora FGV, 2006.

GAMEIRO, A. H. Índice de preço para o transporte de carga: o caso da soja a granel. Tese (Doutorado) - Economia Aplicada - Escola Superior de Agricultura Luiz Queiroz, Universidade de São Paulo. Piracicaba, 2003.

IMEA. Instituto Matogrossense de Economia Agropecuária. Entendendo o Mercado de Soja. Workshop de Jornalismo Agropecuário: Uma oportunidade para sua carreira. Cuiabá, 2015.

KUSSANO, M. R. e BATALHA, M. O. Custos logísticos agroindustriais: avaliação do escoamento da soja em grão do Mato Grosso para o mercado externo. Gest. Prod, v. 19, n. 3, p. 619-632, São Carlos, 2012.

LIMA, M. P. Custeio Rodoviário de transporte de cargas. In: FLEURY, P. F., WANKE, P. e FIGUEIREDO, K. F. (Org.). Logística e gerenciamento da cadeia de suprimentos: planejamento do fluxo de produtos e dos recursos. São Paulo: Atlas, 2006.

OJIMA, A. L. R. O. e YAMAKAMI, A. A otimização logística e a competitividade da soja da região centrooeste: uma aplicação de um modelo de equilíbrio espacial de programação quadrática. Revista de Engenharia Agrícola, Jaboticabal, n. 2, maio/ago. 2006.

ORNAGHI, T. Brasil perde $6 \%$ da safra de grãos com transporte. Jornal Folha de São Paulo, 1 ago. 2004. Disponível em: <http://www1.folha.uol.com.br/fsp/ dinheiro/fi0108200417.htm > . Acesso em: 09 mar. 2015.

PORTER, M. E. Vantagem competitiva: criando e sustentando um desempenho superior. Rio de Janeiro: Editora Campos, 1989.

RICHARDSON, R. J. Pesquisa social: métodos e técnicas. São Paulo: Atlas, 1999. 
ROTA DO OESTE. Site Institucional. Disponível em: <http://www.rotadooeste.com.br/pt-br/rota-dooeste>. Acesso em: 29 nov. 2015.

SEMPREBOM, P. A. Perdas no transporte agrícola. Monografia em Ciência Política e Desenvolvimento Estratégico, Faculdade Arthur Thomas, Londrina, 2009.

SILVA FILHO, R. e LIRIO, V. S. Análise da estrutura de escoamento da soja brasileira em estados selecionados: Mato
Grosso, Paraná e Rio Grande do Sul. Anais do XLII Congresso Brasileiro de Economia e Sociologia Rural, SOBER, Cuiabá, 2004.

TAVARES, C. E. C. Fatores Críticos à Competitividade da Soja no Paraná e no Mato Grosso. CONAB, Brasília, 2004. Disponível em: <http://www.conab.gov.br/conabweb/download/cas/ especiais/trabalho_sobre_competitividade_soja_mt_e_ pr.pdf>. Acesso em: 09 fev. 2016. 
